Samuel Krauss Talmudische Archäologie 2, 429, Anm. 52 gebotenen Stellen und seine diesbezüglichen Ausführungen S. 6 des genannten Bandes. - Für die Verbreitung der Kniestellung der Gebärenden auch bei dén nordischen Germanenstämmen sprechen Eddastellen, wie Oddr. 7, 3 und Sig. sk. 45; vgl. dazu Fritzners Ordbog over det gamle norske sprog 2, 307 a.

Wien.

Rudolf Back.

\title{
Die 2. Pers. Sg. Inf. st. Flexion im Westgermanischen.
}

Wenn im Indikativ des deutschen Verbums irgendwo ein auffallendes $i$ der Endung oder ein befremdlicher Umlaut auftaucht, so hat man gern eine Einwirkung des Opt. angenommen, so bei der in der Überschrift genannten Form, bei wir mügen, sülen, bei mnd. wi weren, bei alem. wir gön, wir lön. An sich sind derartige Erklärungen so unwahrscheinlich als möglich. Der Opt. ist der weitaus seltenere Modus, er geht sogar im Laufe der Zeit in gewissem Umfang gänzlich verloren. Und niemand hat bis jetzt unternommen, das Unwahrscheinliche wahrscheinlich zu machen. So hat man denn auch andere Erklärungen an die Stelle gesetzt. Brenner hat wir mügen aus dem nachstehenden Pronomen erklärt, und ich habe diese Auffassung auf wi weren und wir gön, lön übertragen. Für die 2. Pers. Praet. hat die Deutung von Fierlingers vielfach Beifall gefunden. In einem Fall steht ja der Ersatz der Indikativform durch eine solche des Opt. fest: in der 1. Pers. Pl. Praes. des Verbs bei Notker, vgl. Braune PBB. 2, 138. Ich mache dafür die Berührung der beiden Modi verantwortlich, die sich im Adhortativ vollzieht, vgl. PBB. 43, 324 .

Nunmehr hat Edw. Schröder oben S. 224 einen verlockenden Versuch gemacht, für bâdi zur alten Grimmschen Erklärung zurückzukehren, indem er es als den Optativ der Frage faßt. Er hätte zu Gunsten seiner Auffassung noch geltend machen können, daf man in der Anrede besonders leicht die Frage anwenden wird und vielleicht nicht so häufig Anlaß hat, dem Angeredeten Mitteilung zu machen über das, was or getan hat. 
168 O. Behaghel, Die 2. Pers. Sg. Inf. st. Flexion im Westgermanischen.

Trotzdem ist meines Erachtens Schröders Vermutung unhaltbar, und zwar aus Gründen der Syntax. Schröder hat nach Belegen des Optativs in der direkten Frage innerhalb des Westgermanischen gesucht und solche im Angelsächsischen gefunden. Es ist ihm entgangen, daß ich über diese angelsächsischen Fragesätze in meinem Gebrauch der Zeitformen (1898, S. 182) gehandelt und sie für Nebensätze mit Ersparung des Hauptsatzes erklärt habe; vgl. auch Horn, Anglia, Beibl. 27, 82. Ein Beispiel aus Otfrid, bei dem diese Auffassung wohl ausgeschlossen ist, gewährt Erdmann, Untersuchungen 1, 19: IV, 24, 8 thu sus inan nu lazes? Aber auch dieses Beispiel bietet keine Stütze für Schröder. Denn es besteht im Germanischen ein tiefgreifender Unterschied zwischen Opt. Praes. und Opt. Praet.: potentiale Bedeutung kommt nur dem Opt. Praes. zu, während der Opt. Praet. ausschließlich irreale Bedeutung besitzt, wie ich das in meiner Schrift über den Gebrauch der Zeitformen S. 183 ff. dargelegt habe und wie es in meiner im Druck befindlichen deutschen Syntax $\$ 674$ $\mathrm{zu}$ lesen sein wird.

Man wird daher gut tun, bis auf weiteres zu von Fierlingers Auffassung zurückzukehren.

Ich mache beiläufig darauf aufmerksam, daß man den Untergang der Aoristform im Nordischen und im Gotischen für die ostgermanische Spracheinheit ins Feld führen könnte.

Gießen.

o. Behaghel. 